\title{
openheart Clinical and echocardiographic characteristics of individuals aged 75/76 years old with screening-detected elevated NT-proBNP levels
}

\author{
Faris Al-Khalili (D) , ${ }^{1,2}$ Katrin Kemp-Gudmundsdottir, ${ }^{1}$ Emma Svennberg, ${ }^{1}$ \\ Tove Fredriksson, ${ }^{1}$ Viveka Frykman, ${ }^{1}$ Leif Friberg, ${ }^{1}$ Mårten Rosenqvist, ${ }^{1}$ \\ Johan Engdahl ${ }^{1}$
}

\begin{abstract}
- Additional material is published online only. To view please visit the journal online (http://dx.doi.org/10.1136/ openhrt-2019-001200).
\end{abstract}

To cite: Al-Khalili F, Kemp-Gudmundsdottir $\mathrm{K}$ Svennberg E, et al. Clinical and echocardiographic characteristics of individuals aged $75 / 76$ years old with screening-detected elevated NT-proBNP levels. Open Heart 2020;7:e001200. doi:10.1136/ openhrt-2019-001200

Received 27 October 2019 Revised 15 December 2019 Accepted 5 January 2020

\section{Check for updates}

(C) Author(s) (or their employer(s)) 2020. Re-use permitted under CC BY-NC. No commercial re-use. See rights and permissions. Published by BMJ.

${ }^{1}$ Department of Clinical Sciences, Karolinska Institutet, Danderyd University Hospital, Stockholm, Sweden

${ }^{2}$ Heart, Lung and Allergy Clinic Sophiahemmet Hospital, Stockholm, Sweden

Correspondence to Dr Faris Al-Khalili; faris.alkhalili@hlamottagningen.se

\section{ABSTRACT}

Background High plasma levels of N-terminal pro-Btype natriuretic peptide (NT-proBNP) indicate increased probability of congestive heart failure (CHF) and atrial fibrillation (AF) and are associated with poor prognosis. Objective We aimed to describe the clinical and echocardiographic characteristics of a population of individuals aged 75/76 years old with NT-proBNP $\geq 900 \mathrm{ng} / \mathrm{L}$ without previously known CHF or AF.

Methods All individuals aged $75 / 76$ years in the Stockholm region were randomised to a screening study for AF. Half of them were invited to screening. Of those invited, $49.5 \%$ agreed to participate. Individuals with NTproBNP $\geq 900 \mathrm{ng} / \mathrm{L}$ without known CHF were invited for further clinical evaluation.

Results Among 6315 participants without AF who had NT-proBNP sampled, 102 without previously known CHF had $\geq 900 \mathrm{ng} / \mathrm{L}$. Of these, 93 completed further clinical investigations. In the population that was clinically investigated, $53 \%$ were female, and the median NTproBNP was $1200 \mathrm{ng} / \mathrm{L}$. New AF was found in $28(30 \%)$. The NT-proBNP value in this group was not significantly different from those where AF was not detected (median 1285 vs $1178 \mathrm{ng} / \mathrm{L})$. Patients with newly detected AF had larger left atrial volume and higher pulmonary artery pressure than those without AF. Preserved left ventricular ejection fraction $(\geq 50 \%)$ was found in $86 \%$ of the participants, mid-range ejection fraction (40\%-49\%) in $3.2 \%$ and reduced ejection fraction $(<40 \%)$ in $10.8 \%$. Thirteen patients (14\%) had other serious cardiac disorders that required medical attention.

Conclusion Elderly individuals with NT-proBNP levels $\geq 900 \mathrm{ng} / \mathrm{L}$ constitute a population at high cardiovascular risk even in the absence of diagnosed CHF or AF, and therefore merit further investigation.

\section{INTRODUCTION}

Circulating N-terminal pro-B-type natriuretic peptide (NT-proBNP) is considered an established biomarker of heart failure. ${ }^{1-5} \mathrm{It}$ is also a marker of poor prognosis in populations without a previous diagnosis of heart failure. ${ }^{6}$ Recent focus has been shed on the

\section{Key questions}

What is already known about this subject?

- Circulating N-terminal pro-B-type natriuretic peptide (NT-proBNP) is a biomarker of heart failure and atrial fibrillation, and a marker of poor prognosis.

What does this study add?

- High levels of NT-proBNP levels $\geq 900 \mathrm{ng} / \mathrm{L}$ without previous diagnosis of heart failure or atrial fibrillation in an elderly population may indicate the presence of undiagnosed serious cardiovascular comorbidity, including a high risk for atrial fibrillation.

How might this impact on clinical practice?

- The finding of an NT-proBNP level exceeding $900 \mathrm{ng} / \mathrm{L}$ should merit further cardiovascular workup, in particular for atrial fibrillation, even in asymptomatic individuals.

prognostic value and role of NT-proBNP in the detection of atrial fibrillation (AF) ${ }^{7-9}$ The STROKESTOP I study showed that NT-proBNP plasma levels of $\geq 125 \mathrm{ng} / \mathrm{L}$ can be used to identify individuals at high risk for previously undiagnosed $\mathrm{AF}^{10}$

In the acute setting circulating NT-proBNP levels $>900 \mathrm{ng} / \mathrm{L}$ are highly discriminatory for diagnosis of acute heart failure in patients above 50 years of age. ${ }^{11}$ Similar values have been found in patients with heart failure and preserved left ventricular (LV) function in the non-acute setting. ${ }^{12}$ The benefit of screening for high values of NT-proBNP in an elderly population is largely unknown.

We aimed to investigate the clinical and echocardiographic characteristics of elderly individuals with levels of NT-proBNP $\geq 900 \mathrm{ng} / \mathrm{L}$ in a population-based screening study for AF. 


\section{METHODS}

This is a substudy to the STROKESTOP II trial, which has been described previously. ${ }^{13}$ In summary, all individuals aged 75/76 years old in the Stockholm region $(\mathrm{n}=28$ 712) were randomised $1: 1$ to be invited to a screening programme for $\mathrm{AF}$ or to serve as a control group. Invited participants without prior diagnosis of AF had NT-proBNP analysed and were stratified into two groups: a low-risk group with NT-proBNP $<125 \mathrm{ng} / \mathrm{L}$ and a high-risk group with NT-proBNP $\geq 125 \mathrm{ng} / \mathrm{L}$. The high-risk group was offered extended ECG screening consisting of a 30s ECG obtained with a handheld one-lead device (Zenicor II device, Zenicor Medical Systems, Stockholm, Sweden). The extended ECG recording was continued with the same device four times daily for 2 weeks. A group of the participants were included in a substudy where extended AF screening was performed during a 2-week period with a continuous event-recording device (R-Test 4 Evolution by Novacor). ${ }^{14}$ Patients with NT-proBNP $\geq 900 \mathrm{ng} / \mathrm{L}$ without previously known heart failure were offered an additional cardiovascular clinical examination including standard transthoracic echocardiography. Other diagnostic methods such as stress test, ambulatory continuous ECG recording, MRI and coronary angiography were performed when considered essential. The baseline results of the STROKESTOP II trial are already published. ${ }^{14}$

All echocardiographic examinations were performed using General Electric VIVID 9 device. Experienced sonographers and cardiologists did the assessment of the LV function qualitatively (visually) as referred to eyeballing' '. The left ventricular ejection fraction (LVEF) was categorised into three groups: preserved ejection fraction defined as LVEF $\geq 50 \%$, mid-range as LVEF $40 \%-49 \%$ and reduced as LVEF $<40 \% .^{5}$

The LV cavity dimension and wall thickness were measured at end diastole, in parasternal long-axis view. LV mass was estimated automatically by the software. LV mass index was calculated by dividing LV mass by body surface area. Systolic pulmonary artery pressure was calculated by measuring the maximal tricuspid regurgitant velocity and estimation of right atrial pressure. The left atrium (LA) endocardial border was traced in apical four-chamber and two-chamber views at ventricular end systole. Confluences of LA appendage and pulmonary veins were excluded. The software uses the disk summation method to estimate LA volume. LA volume index was obtained by dividing LA volume by body surface area.

To calculate the E/é ratio, pulse wave (PW)-Doppler of mitral flow was obtained to measure the mitral peak velocity (E), then the average peak early diastolic tissue velocity (é) of the septal and the lateral wall at the level of the mitral annulus was measured using PW-tissue Doppler imaging. All measurements were performed according to the guidelines of the American Society of Echocardiography and the European Association of Cardiovascular Imaging. ${ }^{15}$

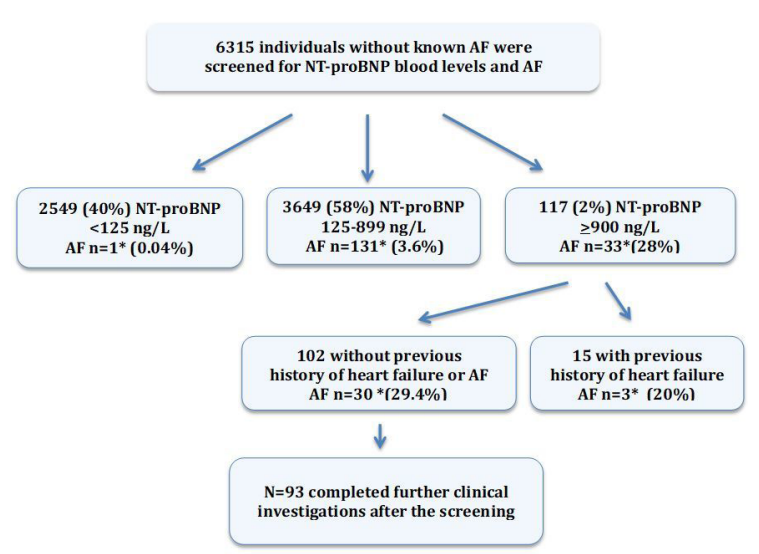

Figure 1 Study flow chart. *Number of patients with newly discovered AF within their respective group (\%). AF, atrial fibrillation; NT-proBNP, N-terminal pro-B-type natriuretic peptide peptide.

No patients nor the public were involved in the design, conduct or reporting, or in the dissemination plans of our research.

\section{Statistics}

Categorical data were summarised by counts and percentages. For all continuous variables, visual inspection of histograms and Shapiro-Wilk's test were used to assess the deviation from a normal distribution. Most of the variables were non-normally distributed; therefore, we decided to report all variables as median with IQR. The CHA2DS2-VASc score was regarded as ordinal data. Fisher's exact test was used to analyse categorical variables. Mann-Whitney U test was used for comparison of the medians between the two groups. $\mathrm{P}$ values $<0.05$ were considered statistically significant.

\section{RESULTS}

The study flow chart and the results of the NT-proBNP analysis and of the extended ECG screening are shown in figure 1. Participants with NT-proBNP $\geq 900 \mathrm{ng} / \mathrm{L}$ and without previously known heart failure $(n=93)$ were clinically examined (including echocardiography) and had a higher proportion of newly discovered AF $(30 \%)$ than those with NT-proBNP 125-900 ng/L (3.6\%). The clinical characteristics of the 93 participants are listed in table 1 . The echocardiographic variables are listed in table 2 . The most common structural abnormality was enlarged LA (58\%). Differences regarding sex, NT-proBNP levels and echocardiographic variables between participants with newly discovered $\mathrm{AF}$ and those without are listed in table 3. Enlarged left atrial volume and elevated pulmonary artery pressure were the echocardiographic characteristics indicative of AF.

There was no difference in AF detection in the group with preserved LVEF (24 of 80, 30\%), compared with mid-range LVEF (1 of 3, 33\%) or with reduced LVEF (3 of $10,30 \%)$. 
Table 1 Clinical features of the clinically examined participants with NT-proBNP $\geq 900 \mathrm{ng} / \mathrm{L}$

\begin{tabular}{lc}
\hline Variables & $\mathbf{n = 9 3}$ \\
\hline Female, $\mathrm{n}(\%)$ & $49(53)$ \\
\hline BMI, median (Q1-Q3) & $24.8(23.2-27.5)$ \\
\hline NT-proBNP, median (Q1-Q3) & $1200(1000-1750)$ \\
\hline New diagnosis of AF, $\mathrm{n}(\%)$ & $28(30)$ \\
\hline Hypertension, $\mathrm{n}(\%)$ & $69(74)$ \\
\hline Diabetes mellitus, $\mathrm{n}(\%)$ & $21(22.6)$ \\
\hline Vascular disease*, $\mathrm{n}(\%)$ & $19(20.4)$ \\
\hline \multicolumn{1}{c}{ Previous AMI, $\mathrm{n}(\%)$} & $11(11.8)$ \\
\hline History of ischaemic stroke/TIA & $11(11.8)$ \\
Glomerular filtration rate, mL/min, median & $64(38-74)$ \\
(Q1-Q3) & $41(44)$ \\
\hline Glomerular filtration rate $<60 \mathrm{~mL} /$ min, $\mathrm{n}(\%)$ & \\
\hline
\end{tabular}

*Previous AMI (Acute Myocardial Infarction), CABG (Coronary ByPass Surgery) or $\mathrm{PCl}$.(Percutanous Coronary Intervention) $\mathrm{AMI}$, acute myocardial infarctio; BMI, body mass index; CABG, coronary by-pass surgery; NT-proBNP, N-terminal pro-type-B natriuretic peptide; $\mathrm{PCl}$, percutaneous coronary intervention; $\mathrm{Q} 1$, first quartile; Q3, third quartile; TIA, transitory ischaemic attack.

There were no significant differences in NT-proBNP level in the group with reduced LVEF (median 1380 ng/L, IQR 1088-1600), compared with mid-range LVEF (median $1200 \mathrm{ng} / \mathrm{L}$, IQR 1000-1400) and those with preserved LVEF (median $1185 \mathrm{ng} / \mathrm{L}$, IQR 1000-1813).

Among the 93 patients who underwent extended cardiovascular examination, 13 were found to have additional clinically relevant comorbidity, apart from the newly discovered $\mathrm{AF}$, as listed in table 4. In addition,

Table 2 Echocardiographic findings in the clinically examined group of participants with NT-proBNP $\geq 900 \mathrm{ng} / \mathrm{L}$ $(\mathrm{n}=93)$

\begin{tabular}{ll}
\hline \multicolumn{2}{l}{ Echocardiographic variables } \\
\hline LVEF $\geq 50 \%, \mathrm{n}(\%)$ & $80(86)$ \\
\hline LVEF $40 \%-49 \%, \mathrm{n}(\%)$ & $3(3.2)$ \\
\hline $\mathrm{LVEF}<40 \%, \mathrm{n}(\%)$ & $10(10.8)$ \\
\hline Atrial volume $\mathrm{mL} / \mathrm{m}^{2}$, median $(\mathrm{Q} 1-\mathrm{Q} 3)$ & $36(30-48)$ \\
\hline Left ventricular mass, $\mathrm{g} / \mathrm{m}^{2}$, median $(\mathrm{Q} 1-\mathrm{Q} 3)$ & $96(80-124.5)$ \\
\hline Mitral E/é ratio, median $(\mathrm{Q} 1-\mathrm{Q} 3)$ & $11.2(9-14)$ \\
\hline Pulmonary artery pressure, $\mathrm{mm} \mathrm{Hg}$, median $(\mathrm{Q} 1-\mathrm{Q} 3)$ & $33(28.8-39.5)$ \\
\hline Patients with atrial volume $>34 \mathrm{~mL} / \mathrm{m}^{2}, \mathrm{n}(\%)$ & $53(58)$ \\
\hline $\begin{array}{l}\text { Patients with left ventricular mass }>115 \mathrm{~g} / \mathrm{m}^{2} \text { in men } \\
\text { and }>95 \mathrm{~g} / \mathrm{m}^{2} \text { in women, } \mathrm{n}(\%)\end{array}$ & $33(41.3)$ \\
\hline Patients with E/é $>13, \mathrm{n}(\%)$ & $28(39)$ \\
\hline $\begin{array}{l}\text { Patients with pulmonary artery pressure }>35 \mathrm{~mm} \mathrm{Hg}, \\
\mathrm{n}(\%)\end{array}$ & $27(39)$ \\
\hline
\end{tabular}

é, average peak early diastolic tissue velocity; E, mitral peak velocity; LVEF, left ventricular ejection fraction; NT-proBNP, Nterminal pro-B-type natriuretic peptide; Q1, first quartile; Q3, third quartile. two participants suffered from ischaemic stroke and one patient from acute myocardial infarction within 2 months after NT-proBNP screening.

The methods of detection, frequency and the duration of AF are described in detail in online supplementary table 1.

Our main finding is that a high proportion of individuals participating in a systematic screening programme with NT-proBNP $\geq 900 \mathrm{ng} / \mathrm{L}$ had previously undiagnosed $\mathrm{AF}$ on examination. This was significantly higher than among individuals with lower levels of NT-proBNP and other screened populations of the same age group. ${ }^{16} 17$ Although only $2 \%$ of the study population had NT-proBNP $\geq 900 \mathrm{ng} / \mathrm{L}$, these individuals often had significant comorbidity, making it a high-risk population in need of further clinical investigations and extended follow-up.

We found no differences in the proportion of patients with new AF between the different LVEF groups, which may have been due to few individuals with intermediate or reduced LVEF in the study, as patients with known congestive heart failure were not included. This lack of relation between AF and reduced LVEF was also observed in two large registry studies in which $\mathrm{AF}$ was more common with increasing LVEF. ${ }^{1819}$ Other studies have shown a close relation between $\mathrm{AF}$ and heart failure with preserved systolic function, especially in elderly populations. ${ }^{20}$ However, we found no association between NT-proBNP levels and the likelihood of finding AF, or between NT-proBNP levels and LVEF, which could be due to the small sample size or the lack of discriminatory effect due to the already high threshold of NT-proBNP. This finding is in contrast to the results of the STROKESTOP I study, in which a relation between NT-proBNP levels and newly discovered AF was found. This may possibly be due to a larger sample size. ${ }^{10}$

The high proportion of individuals with newly detected $\mathrm{AF}$ in our study population might be due to common underlying cardiovascular abnormalities which lead to increased levels of NT-proBNP and to the development of $\mathrm{AF}$ and heart failure. The ORBIT AF (Outcomes Registry for Better Informed Treatment of Atrial Fibrillation) trial found an association between NT-proBNP levels and increased risk of AF progression and cardiovascular outcomes. ${ }^{21}$

Multiple comorbidities, especially cardiovascular, were found among patients with high NT-proBNP. Various cardiac conditions, ${ }^{22}$ such as amyloidosis ${ }^{23-25}$ and valvular heart disease, ${ }^{25} 26$ are associated with high NT-proBNPlevels. Impaired renal function can also be a cause of increased levels of NT-proBNP. ${ }^{27}$ These findings show the need for a thorough follow-up in elderly patients with elevated circulating levels of NT-proBNP since the underlying cause could be a serious cardiovascular disorder.

It is worth mentioning that cardiac arrhythmias other than AF may also be a cause of elevated NT-proBNP. ${ }^{28}$ Long-term ECG recordings in these patients revealed not only a high proportion of new AF, but also bradycardia necessitating pacemaker implantation in some patients.

Large LA was closely related to the presence of AF, which is in agreement with previous published observations in 
Table 3 Clinical and echocardiographic differences between participants with new discovered atrial fibrillation and those without $(n=93)$

\begin{tabular}{|c|c|c|c|}
\hline & AF (28) & Non-AF (65) & $P$ value \\
\hline Female, $\mathrm{n}(\%)$ & $15(55.6)$ & $34(52)$ & ns \\
\hline NT-proBNP level, median (Q1-Q3) & $1284.5(1015-2000)$ & 1178 (989.5-1531) & ns \\
\hline Hypertension, n (\%) & $21(75)$ & $48(37.9)$ & ns \\
\hline Diabetes mellitus, n (\%) & $6(21.4)$ & $15(23.1)$ & ns \\
\hline Vascular disease, n (\%) & $4(4.3)$ & $15(16.1)$ & ns \\
\hline Glomerular filtration rate, median (Q1-Q3) & $65(50-77)$ & $62(44-73)$ & ns \\
\hline Body mass index, median (Q1-Q3) & $24.7(23.6-27.9)$ & $25.2(22.4-27.5)$ & ns \\
\hline Left atrial volume index, $\mathrm{mL} / \mathrm{m}^{2}\left(2^{*}\right)$, median (Q1-Q3) & $44(35.00-50.20)$ & $34(29.00-41.50)$ & 0.002 \\
\hline Left ventricular mass $\left(13^{\star}\right)$, median (Q1-Q3) & $96(72.00-123.00)$ & $96(83.00-137.00)$ & ns \\
\hline E/é ratio $\left(21^{\star}\right)$, median $(Q 1-Q 3)$ & $13(9.2-14.30)$ & $11(9.00-14.00)$ & ns \\
\hline Pulmonary artery pressure mm Hg, median (Q1-Q3) & $38(30.00-41.00)$ & $32(26.00-36.00)$ & 0.025 \\
\hline
\end{tabular}

*Missing data (inadequate echocardiographic view).

é, average peak early diastolic tissue velocity; AF, atrial fibrillation; E, mitral peak velocity; NT-proBNP, N-terminal pro-B-type natriuretic peptide; Q1, first quartile; Q3, third quartile.

\begin{tabular}{|c|c|c|c|}
\hline Number & Comorbidity & $\begin{array}{l}\text { NT-proBNP } \\
\text { (ng/L) }\end{array}$ & Measure \\
\hline 1 & Severe aortic stenosis & 1015 & $\begin{array}{l}\text { Aortic valve } \\
\text { replacement }\end{array}$ \\
\hline 2 & Severe aortic stenosis & 1200 & $\begin{array}{l}\text { Aortic valve } \\
\text { replacement }\end{array}$ \\
\hline 3 & $\begin{array}{l}\text { Moderate aortic } \\
\text { stenosis }\end{array}$ & 2500 & Follow-up \\
\hline 4 & $\begin{array}{l}\text { Severe aortic } \\
\text { regurgitation }\end{array}$ & 940 & $\begin{array}{l}\text { Aortic valve } \\
\text { replacement }\end{array}$ \\
\hline 5 & $\begin{array}{l}\text { Moderate aortic } \\
\text { regurgitation }\end{array}$ & 3936 & Follow-up \\
\hline 6 & Sick sinus syndrome & 1010 & Pacemaker \\
\hline 7 & Sick sinus syndrome & 2133 & Pacemaker \\
\hline 8 & $\begin{array}{l}\text { Hypertrophic } \\
\text { obstructive } \\
\text { cardiomyopathy }\end{array}$ & 1200 & Follow-up \\
\hline 9 & $\begin{array}{l}\text { Severe chronic renal } \\
\text { failure* }^{*}\end{array}$ & 3258 & Dialysis \\
\hline 10 & Amyloidosis & 1400 & Follow-up \\
\hline 11 & Amyloidosis & 912 & Follow-up \\
\hline 12 & Amyloidosis & 1917 & Follow-up \\
\hline 13 & $\begin{array}{l}\text { Angina pectoris with } \\
\text { significant ischaemic } \\
\text { coronary heart disease }\end{array}$ & 1000 & $\begin{array}{l}\text { PCI of significant } \\
\text { LAD stenosis }\end{array}$ \\
\hline
\end{tabular}

*Glomerular filtration rate $<10 \mathrm{~mL} / \mathrm{min}$.

LAD, left anterior descending coronary artery; NT-proBNP, Nterminal pro-B-type natriuretic peptide; $\mathrm{PCl}$, percutaneous coronary intervention. the general AF population and in patients with congestive heart failure. ${ }^{29-31}$ Another variable which differed between the two groups in our study was elevated pulmonary artery pressure in the AF population compared with the patient group without. It has previously been reported that $\mathrm{AF}$ is common among patients with pulmonary hypertension. ${ }^{32}$

Interestingly, most of our patients had normal systolic LV function. This finding could put the validity of NT-proBNP as a screening biomarker for impaired systolic LV function into question. However, a large proportion of the participants had abnormal structural findings or findings suggestive of diastolic dysfunction, which is common among patients with heart failure and preserved LVEF; hence, echocardiography is well merited in this group. In our population $\mathrm{AF}$ was a common finding, and increased levels of NT-proBNP might reflect arrhythmia rather than systolic dysfunction.

A limitation is that our results refer to individuals of a certain age group with abnormally high levels of NT-proBNP detected by screening rather than in conjunction with spontaneous healthcare contacts due to symptoms. The results therefore have to be interpreted with caution and may not be directly generalisable to other populations.

Optimal echocardiographic views for adequate analysis could not be obtained in all patients and there could have been some intervariability in the results. Another limitation is that the screening for AF was done using intermittent ECG for 2 weeks, which could have missed some AF episodes and thus underestimated the number of individuals with newly detected AF. 


\section{CONCLUSION}

When screening for silent cardiac disorders in an elderly population, high levels of circulating NT-proBNP indicate a need for further clinical action to search for the presence of undiagnosed serious cardiovascular comorbidities, particularly AF.

Contributors FA-K: conceptualisation, conduct, acquisition, methodology, validation, visualisation, writing, review and editing, and responsible for the overall content. KK-G: conceptualisation, acquisition, methodology, validation, and review and editing. ES, MR: conceptualisation, funding, acquisition, methodology, and review and editing. TF, VF, LF: conceptualisation, acquisition, methodology, and review and editing. JE: conceptualisation, acquisition, methodology, funding, and review and editing.

Funding The study was funded by Roche Diagnostics, Carl Bennet AB, and The Swedish Heart and Lung Foundation. JE and ES were supported by the Stockholm County Council (clinical research appointment).

Competing interests FA-K has received lecture fees from Bayer, Boehringer Ingelheim and BMS/Pfizer. KK-G has received a research grant from Stiftelsen Hjärtat and received lecture fees from BMS/Pfizer. ES has received lecture fees from Bayer, Bristol-Myers Squibb-Pfizer, Boehringer Ingelheim and Sanofi. LF has received consultancy fees from Bayer, Boehringer Ingelheim, BMS/Pfizer and Sanofi. TF has received unrestricted research grants from Boehringer Ingelheim and Stiftelsen Hjärtat. VF has received lecture fees from Merck Sharp \& Dohme, Boehringer Ingelheim, Bayer and Medtronic. JE has received consultancy fees from Bristol-Myers Squibb and Pfizer, lecture fees from Merck Sharp \& Dohme and Medtronic, and unrestricted research grants from Pfizer. MR received consultancy and lecture fees from Medtronic, Zenicor, Bayer, Boehringer Ingelheim, Pfizer, Bristol-Myers Squibb and Abbott, and research grants from Roche Diagnostics, Bristol-Myers Squibb, Sanofi, Boehringer Ingelheim and Bayer.

Patient consent for publication Not required.

Ethics approval Informed consent was obtained from all patients. The study was approved by the Regional Ethical Review Board (DNR 2015/2079-31/1) and conformed to the Declaration of Helsinki.

Provenance and peer review Not commissioned; externally peer reviewed.

Data availability statement Data are available upon reasonable request. Pseudonymised individual data will be available upon request.

Open access This is an open access article distributed in accordance with the Creative Commons Attribution Non Commercial (CC BY-NC 4.0) license, which permits others to distribute, remix, adapt, build upon this work non-commercially, and license their derivative works on different terms, provided the original work is properly cited, appropriate credit is given, any changes made indicated, and the use is non-commercial. See: http://creativecommons.org/licenses/by-nc/4.0/.

\section{ORCID iD}

Faris Al-Khalili http://orcid.org/0000-0002-8849-7052

\section{REFERENCES}

1 Benmachiche M, Marques-Vidal P, Waeber G, et al. In-Hospital mortality is associated with high NT-proBNP level. PLoS One 2018;13:e0207118.

2 Omland T, Aakvaag A, Bonarjee VV, et al. Plasma brain natriuretic peptide as an indicator of left ventricular systolic function and longterm survival after acute myocardial infarction. Comparison with plasma atrial natriuretic peptide and $\mathrm{N}$-terminal proatrial natriuretic peptide. Circulation 1996;93:1963-9.

3 van Veldhuisen DJ, Linssen GCM, Jaarsma T, et al. B-Type natriuretic peptide and prognosis in heart failure patients with preserved and reduced ejection fraction. J Am Coll Cardiol 2013;61:1498-506.

4 Aimo A, Januzzi JL, Vergaro G, et al. High-Sensitivity troponin T, NTproBNP and glomerular filtration rate: a multimarker strategy for risk stratification in chronic heart failure. Int J Cardiol 2019;277:166-72.

5 Ponikowski P, Voors AA, Anker SD, et al. 2016 ESC Guidelines for the diagnosis and treatment of acute and chronic heart failure: The Task Force for the diagnosis and treatment of acute and chronic heart failure of the European Society of Cardiology (ESC)Developed with the special contribution of the Heart Failure Association (HFA) of the ESC. Eur Heart J 2016;37:2129-200.

6 York MK, Gupta DK, Reynolds CF, et al. B-Type Natriuretic Peptide Levels and Mortality in Patients With and Without Heart Failure. J Am Coll Cardiol 2018;71:2079-88.
7 Hijazi Z, Oldgren J, Lindbäck J, et al. A biomarker-based risk score to predict death in patients with atrial fibrillation: the ABC (age, biomarkers, clinical history) death risk score. Eur Heart $J$ 2018;39:477-85.

8 Hijazi Z, Wallentin L. Natriuretic peptide should be used as a routine tool for evaluation of patients with atrial fibrillation. Heart 2018:heartjnl-2018-314040.

9 Sharma A, Hijazi Z, Andersson U, et al. Use of biomarkers to predict specific causes of death in patients with atrial fibrillation. Circulation 2018;138:1666-76.

10 Svennberg E, Henriksson P, Engdahl J, et al. N-Terminal pro B-type natriuretic peptide in systematic screening for atrial fibrillation. Heart 2017;103:1271-7.

11 Januzzi JL, Camargo CA, Anwaruddin S, et al. The N-terminal ProBNP investigation of dyspnea in the emergency department (pride) study. Am J Cardiol 2005;95:948-54.

12 Solomon SD, Rizkala AR, Lefkowitz MP, et al. Baseline characteristics of patients with heart failure and preserved ejection fraction in the PARAGON-HF trial. Circulation 2018;11:e004962.

13 Engdahl J, Svennberg E, Friberg L, et al. Stepwise mass screening for atrial fibrillation using $\mathrm{N}$-terminal pro B-type natriuretic peptide: the STROKESTOP II study design. Europace 2017;19:297-302.

14 Kemp Gudmundsdottir K, Fredriksson T, Svennberg E, et al. Stepwise mass screening for atrial fibrillation using N-terminal Btype natriuretic peptide: the STROKESTOP II study. EP Europace 2019:pii: euz255.

15 Lang RM, Badano LP, Mor-Avi V, et al. Recommendations for cardiac chamber quantification by echocardiography in adults: an update from the American Society of echocardiography and the European association of cardiovascular imaging. Eur Heart $J$ Cardiovasc Imaging 2015;16:233-71.

16 Svennberg E, Engdahl J, Al-Khalili F, et al. Mass screening for untreated atrial fibrillation: the STROKESTOP study. Circulation 2015;131:2176-84.

17 Ghazal F, Theobald H, Rosenqvist M, et al. Feasibility and outcomes of atrial fibrillation screening using intermittent electrocardiography in a primary healthcare setting: a cross-sectional study. PLoS One 2018;13:e0198069.

18 Sartipy U, Dahlström U, Fu M, et al. Atrial fibrillation in heart failure with preserved, Mid-Range, and reduced ejection fraction. JACC Heart Fail 2017;5:565-74.

19 Zafrir B, Lund LH, Laroche C, et al. Prognostic implications of atria fibrillation in heart failure with reduced, mid-range, and preserved ejection fraction: a report from 14964 patients in the European Society of Cardiology Heart Failure Long-Term Registry. Eur Heart J 2018;39:4277-84.

20 Kotecha D, Lam CSP, Van Veldhuisen DJ, et al. Heart Failure With Preserved Ejection Fraction and Atrial Fibrillation. J Am Coll Cardiol 2016;68:2217-28.

21 Inohara T, Kim S, Pieper K, et al. B-Type natriuretic peptide, disease progression and clinical outcomes in atrial fibrillation. Heart 2019;105:370-7.

22 Burke MA, Cotts WG. Interpretation of B-type natriuretic peptide in cardiac disease and other comorbid conditions. Heart Fail Rev 2007;12:23-36

23 Jonker DL, Hazenberg BPC, Nienhuis HLA, et al. Imaging cardiac innervation in hereditary transthyretin (ATTRm) amyloidosis: a marker for neuropathy or cardiomyopathy in case of heart failure? $\mathrm{J} \mathrm{Nucl}$ Cardiol 2018;349.

24 Palladini G, Campana C, Klersy C, et al. Serum N-terminal Pro-Brain natriuretic peptide is a sensitive marker of myocardial dysfunction in al amyloidosis. Circulation 2003;107:2440-5.

25 Nordlinger M, Magnani B, Skinner M, et al. Is elevated plasma Bnatriuretic peptide in amyloidosis simply a function of the presence of heart failure? Am J Cardiol 2005;96:982-4.

26 Weber M, Arnold R, Rau M, et al. Relation of N-terminal Pro-BType natriuretic peptide to severity of valvular aortic stenosis. Am J Cardiol 2004;94:740-5.

27 Vickery S, Price CP, John RI, et al. B-Type natriuretic peptide (BNP) and amino-terminal proBNP in patients with CKD: relationship to renal function and left ventricular hypertrophy. Am J Kidney Dis 2005;46:610-20.

28 Kuo J-Y, Wang A-M, Chang S-H, et al. Responses of cardiac natriuretic peptides after paroxysmal supraventricular tachycardia: ANP surges faster than BNP and CNP. Am J Physiol Heart Circ Physiol 2016;310:H725-31.

29 Njoku A, Kannabhiran M, Arora R, et al. Left atrial volume predicts atrial fibrillation recurrence after radiofrequency ablation: a metaanalysis. Europace 2018;20:33-42. 
30 Kannel WB, Wolf PA, Benjamin EJ, et al. Incidence, prognosis, and predisposing conditions for atrial fibrillation: population-based estimates. Am J Cardiol 1998;82:2-9.

31 Lam CSP, Rienstra M, Tay WT, et al. Atrial fibrillation in heart failure with preserved ejection fraction: association with exercise capacity, left ventricular filling pressures, natriuretic peptides, and left atrial volume. JACC Heart Fail 2017;5:92-8.

32 Rottlaender D, Motloch LJ, Schmidt D, et al. Clinical impact of atrial fibrillation in patients with pulmonary hypertension. PLoS One 2012;7:e33902 